\title{
Europe urged to set common science teaching standards
}

Lisbon. The European Union (EU) has been urged to fix minimum standards for the amount of funding, equipment and staff allocated to science education in its member states in a report on science education and culture presented this week to Antonio Ruberti, the outgoing EU research commissioner.

The report recommends that the EU should promote scientific literacy through cooperation between teachers, education specialists and museums and industry across Europe, using a model based on the Eureka programme for inter-country collaboration on high-technology projects.

It also suggests that schools should be encouraged to build closer links with informal education media, such as hands-on science centres, museums, science clubs and youth networks, and to give pupils first-hand experience of experimental and investigative work.

The report was compiled from data from individual member states by Joan Salomon, of the education department at the University of Oxford, and presented in draft form to a conference in Lisbon last month.

It stems from a project, financed by the EU(ECU150,000) and the Calouste Gulbenkian Foundation (ECU75,000), and coordinated by José Mariano Gago, professor of physics at the University of Lisbon, and director of the Instituto Prospectivo in Lisbon.

The report says it is "fundamentally important" for Europeans to deepen their scientific culture as they increasingly have to decide on issues that need "both scientific knowledge and a positive, unfrightened attitude towards science and technology"

David Bricknell, director of science and technology at the European Chemical Industry Council (CEFIC), told the Lisbon meeting that the lack of scientific culture in Europe, and the public's negative perception of the chemical industry, poses a serious threat to Europe's "industrial survival".

$\mathrm{He}$ added that European industry believes standards of science education are falling, that this could lead to a lack of innovative scientists. According to Bricknell, public opinion surveys carried out by CEFIC show that the level of knowledge about chemical issues has deteriorated over the last 10 years.

But Salomon emphasized that the aim of creating a scientific culture is not merely to create a public that accepts scientific innovation, but to give people the knowledge to question and discuss advances, for example in biotechnology.

The report also showed that all EU member states have a national curriculum specifying the amount of science that should be taught in secondary schools. But working groups from the member states said that science should be given more emphasis in elementary schools, and made more relevant to children's everyday lives, for example by relating teaching points to technologies and issues that surround them, such as the environment and computer and video games.

In particular, they recommended experimental work as a way of interesting pupils in science. Gago points out that in some countries such work, while recommended, is not compulsory, and rarely takes place when facilities are lacking, as in Portugal.

The conference also emphasized the discrepancies between European countries on the funding of education. As science and technology subjects are relatively expensive to teach, the less a country spend over-

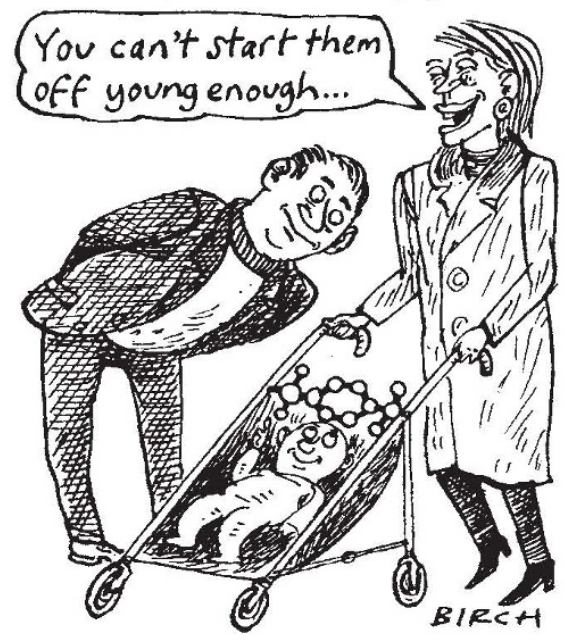

all, the more science education is likely to suffer. In order to move towards a common level of science education across Europe, the conference called for the setting of minimum standards for facilities.

The groups also drew attention to the poor training of science teachers in many European countries, pointing out that in some countries teachers have to teach science subjects in which they have no training. "Science is not held in the same high esteem as it once was," complained Edward Jenkins, chairman of the school of education at the University of Leeds in the United Kingdom.

Harold Stevenson, an educational psychologist at the University of Michigan Ann Arbor, claimed that attempts to improve science education will be "fruitless" unless the status of teachers is improved. If science departments are not adequately funded, he said, pupils will see this as a reflection of the lack of importance attached to that subject by the school, their parents and society as a whole and this will affect their attitudes to science.
Maggie Verrall

\section{Unilever consigns manganese catalyst to the back-burner}

London. Unilever, the Anglo-Dutch consumer products company, last week effectively consigned to the sidelines products containing a controversial manganese-based catalyst that it had previously hailed as a radical innovation in the detergent market.

Last May the company launched a series of products containing the new catalyst, reputed to have cost more than $£ 100$ million to develop. The catalyst, which removes stains faster and at lower temperatures than traditional formulations, is a heterocyclic complex of manganese that promotes the selective oxidation of stains by hydrogen peroxide (see Nature 369,511 ; 1994).

But its US-based rival Procter \& Gamble immediately claimed that the catalyst could damage clothes through repeated washing, backing this up with reports from independent research institutes.

Unilever is launching a new detergent, New Generation Persil, in the United Kingdom in February, and in the rest of Europe in the following months. It will not contain the manganese catalyst, which is being restricted to specialist uses.

Maggie Verrall

\section{Neuroscientist tipped as new Science editor}

Washington. Science is expected to name Floyd Bloom, a neuroscientist at the Scripps Research Institute, La Jolla, California, as its next editor-in-chief, sources close to the magazine say.

58 -year-old Bloom is understood to be in contract negotiations with the American Association for the Advancement of Science (AAAS), which runs the weekly journal from Washington.

AAAS spokeswoman Nan Broadbent said that the organization was in negotiations with one individual, but refused to confirm who it was. Bloom was on travel earlier this week and unavailable for comment.

Bloom spent much of his early career with the National Institute of Mental Health at St Elizabeth's Hospital in Washington, before moving to the Salk Institute, San Diego, in 1975, and to Scripps in 1983.

A past chairman of the neurobiology section at the National Academy of Sciences, he has been highly active in various professional bodies including the AAAS, is described as well-connected politically, and was heavily involved in the initiative to designate the 1990s "the decade of the brain". Colin Macilwain 